\title{
Identifying Effective Factors on Technological Entrepreneurship in Iranian Nanotechnology SMEs
}

\author{
Mahdi Pakrad*, Seyyed Reza Hejazi, Reza Mohammad Kazemi \\ University of Tehran, Iran \\ *mahdipakrad@ut.ac.ir
}

\begin{abstract}
Technological entrepreneurship is the latest issue in the field of entrepreneurship and fostering competitive advantages in Small and Medium Enterprises (SMEs) which has been received special attention. Given the lack of coherent literature review to apply technological strategies in SMEs, and also because of the role of technology based firms which are active in industries with new technologies, such as Nano-Technology industry, while the technological entrepreneurship literature review has been investigated, this article is principally intended to identify effective factors on technological entrepreneurship in Iranian Nanotechnology SMEs. The research methodology of the current article is a mixed one; in the qualitative stage, semi-structured and open interviews and investigation of related documents have been used, and in the quantitative stage, the questionnaire has been applied to gather data. In the research's quantitative stage, a statistical population consisted of managers, expert employees of the case study have been considered, and the simple random sampling method has been used. In addition, in this stage, the questionnaires have been used as the data collection tool and the experts in the qualitative stage measured the research's validity, and the questionnaire's reliability has been approved through Cronbach's alpha of 0.81 . The mean analysis has been applied in this stage for the data analysis. The findings of this paper shows that the effective factors on technological entrepreneurship in Iranian Nanotechnology SMEs are categorizes in the four issues of "Internal Processes", "Individual Factors", "Institutions" and "External Networks".
\end{abstract}

Keywords: Technological Entrepreneurship, Iranian Nanotechnology Industry, SMEs, Effective Factors,

\section{Introduction}

The importance of implementing modern and practical technologies in organizations is undeniable given the complex and dynamic conditions of today's environment. For the purpose of effective and timely implementation in new technologies commercialization and gaining competitive advantage, organizations need to exploit both their internal and external resources (Zahra \& Nielson, 2002). Among the most important characteristics of the world today are vast changes, growing complexities and competitions. Today organizations act in complex and dynamic environment. Huge and continuous evolutions characterize the business environment and highlight the urge of being in harmony with it (Worthington \&Britton, 2006). In such transition, the attention of scientific societies has been drawn to the concept of "entrepreneurship" as a solution to keep and improve business success indexes. Decades after its emergence, the concept of entrepreneurship has found its way into many branches of science and thought and has secured a high status. Among the most important related fields is "Technological Entrepreneurship" which has been received special attention. "Technological Entrepreneurship" follows two major missions. Firstly, by accelerating the conversion of knowledge into technology attempts to satisfy the needs of society; secondly, by implementing these new technologies and applications it seeks better establishment, development or management of organizations (Blanco, 2007). Thus, bearing in mind that the subject of technology entrepreneurship is still emerging, and considering the theoretical and operational deficiencies in the commonalities of technical entrepreneurship, also with regards to the pioneering role of Iranian nanotechnology industry as one of the advanced, modern and renowned industries in the world, the purpose of this article is identifying the effective factors on technological entrepreneurship in Iranian Nanotechnology SMEs ${ }^{1}$.The main question of the present article is that: What are the effective factors on technological entrepreneurship in Iranian Nanotechnology SMEs? In the following, theoretical basis and background is given. After that, research method and data gathering will be discussed. Then, findings of the research will be examined based on content analysis by mixed

\footnotetext{
${ }^{1}$ Small and Medium Enterprises
} 
research method. In the end, findings will be analyzed based on each of the main factors taken from the research and finally the suggestions will be made.

\section{Literature Review}

Technological Entrepreneurship: Many definitions have been suggested for technological entrepreneurship. Dorf \& Byres (2005), define technological entrepreneurship as a business leadership style, which includes identifying technological opportunities with high growth potential, gathering resources such as capital and experts, and finally managing the rapid growth and its significant risk by exploiting special decision-making abilities. Shane \& Venkataraman (2003), see technological entrepreneurship as processes within entrepreneurial organizations during which, entrepreneurs, organizational resources, technological systems and strategies for achieving the opportunities are applied. Petti (2009), suggests two basic features for technological entrepreneurship: potential future benefit, and extreme uncertainty. According to him, technological entrepreneurs intend to create and acquire economic value by excavating and exploiting technology-based solutions (Peng \& Zhang, 2008). Technological entrepreneurship could in fact be considered as an important alternative for individuals and firms entering new markets or new business fields. The market position of individuals and firms is determined by commercialization of technologies rather than business or trade. Thus, some scholars define technological entrepreneurship as follows: "the method and process of discovery, exploitation, and exploration of market opportunities for technologies" (Peng \& Zhang, 2008). Technological entrepreneurship is comprised of two concepts: "technology" and "entrepreneurship". "Technology" is defined as "theoretical and practical knowledge, skills and tools for creation and development of products and services" (Burgelman, Christensen, \& Wheelwright, 2004). Based on these two concepts, Petti (2009) defines technological entrepreneurship as identification, discovery and even creation of entrepreneurial opportunities based on technological development." Regarding the development of knowledge-based economies and the growing importance of modern technologies application in economic growth, technological entrepreneurship broadens and covers new aspects every day. The substantial implication of this concept is that, technological entrepreneurship attempts to bridge the gap between technology development and business creation (value creation in general). Technological entrepreneurship is a process, which starts with the understanding of new technology and even creation of technological opportunities resulting from new discoveries. After linking market needs with these technologies, technological entrepreneurship exploits technological opportunities by the introduction of new products and services (Blanco, 2007). In fact, when various beliefs about the future value of a new or existing technology emerge, technology-based entrepreneurial opportunities are born (Petti \& Zhang. 2011b).

In summary, technological entrepreneurship has several interrelated aspects. First, it is not just about discovery and speculation; rather it includes creation and development as well. Such creation and development occur when different actors get involved with emerging technological paths. Second, these actors are enclosed in the inputs they have generated by being involved in the technological path; at this stage, actors in the knowledge body act as technology output. Third, these processes could differ relative to technological path and each could represent a specific logic (Garud \& Karnoe, 2003). In truth, these opportunities do not appear on their own, and are not the result of talented, creative individuals or teams. Rather, the emergence and exploitation of technical opportunities is the result of a set of systematic activities comprising actors presenting appropriate resources and conditions, which cause the development and distribution of practical technology programs and are therefore considered as a system. This system requires interaction among talented individuals, governmental organizations, educational and research institutions, enterprises and investors that significantly facilitate, stimulate and distribute discoveries and technologies from where they were developed to where they are needed (Petti \& Zhang, 2011a). In general, due to its key role in new economy, technological entrepreneurship has recently attracted the attention of technological entrepreneurship scholars in industrial sections (Peng \& Zhang, 2008). However, the knowledge about technological entrepreneurship and its regional aspects is still insignificant. However, importance and desire for technology-based entrepreneurship is growing and technology-based firms have attracted a lot of attention (Dahlstrand, 2007).

\section{Methodology}

The paper with respect to goal is an applied study and its research methodology is a combined one. Documentary studies and interviews have been used in the qualitative of stage of collecting the data, and in the quantitative stage, questionnaires have been used. The statistical population of the study in the 
qualitative stage is experts and scholars active in technological entrepreneurship with academic experiences or experiences in consulting or organizations and using purposeful sampling after conducting 16 interviews the data have been repeated and in other words collecting the data reached saturation point. In the quantitative stage, the statistical population is a combination of experts and senior managers of the Nanotechnology SMEs. For sampling, the Cochran method has been used that regarding the population of 120 -Frms, the statistical sample of this paper according to the sample volume estimation formula has been limited in the population and it is equal to 67 SMEs. The questionnaires have been sent to these firms and 63 of them have been returned. To measure the amount of importance of each one of the dimensions of the questionnaire, the Likert scale has been used that has an orderly index and by appointing numbers 1 to 5 to the options, the data have been converted to quantitative data. The content validity has been applied in the study. To measure the content validity we refer to the opinion of 16 people of the experts in the qualitative stage in which the subjects and dimensions have been examined and verified. To assess the reliability of the tools the Cronbach's Alpha method has been used and the amount of Cronbach's alpha that indicates the reliability of the questionnaire is 0.81 that is acceptable as it is larger than 0.7 . This study faced limitations with respect to availability of scholars, and regarding the newness of the study topic, it was difficult to find experts on the subject. On the other hand, there should be more studies to test the findings of this research in different environments and examine its generalization.

Table 1: Effective dimensions on technological entrepreneurship

\begin{tabular}{|c|c|c|}
\hline Dimensions & Definitions & Authors \\
\hline Institutions & $\begin{array}{l}\text { Creating } \\
\text { environments }\end{array}$ & $\begin{array}{l}\text { Prodan (2007); Peng \& Zhang } \\
\text { (2008); Peng, Ni \& Yao (2008); } \\
\text { Zhang, Peng \& Li (2008) }\end{array}$ \\
\hline Business Skills & $\begin{array}{l}\text { Not only focus on technical } \\
\text { innovation and social knowledge } \\
\text { is needed }\end{array}$ & $\begin{array}{l}\text { Menzel, Aaltio \& Ulijn (2007); } \\
\text { Prodan (2007) }\end{array}$ \\
\hline $\begin{array}{l}\text { Business Model } \\
\text { Organizational Structure }\end{array}$ & $\begin{array}{l}\text { Revision to the strategies and } \\
\text { organizational changes }\end{array}$ & $\begin{array}{ll}\text { Petti } & \text { (2009) Menzel, Aaltio \& } \\
\text { Ulijn } & \text { (2007); Shane \& }\end{array}$ \\
\hline Firm strategies & $\begin{array}{l}\text { Reducing the uncertainty and } \\
\text { managing the flow of knowledge }\end{array}$ & $\begin{array}{l}\text { Venkataraman (2003) } \\
\text { Petti (2009); Shane \& } \\
\text { Venkataraman }(2003)\end{array}$ \\
\hline Complementary Resources & $\begin{array}{l}\text { Access to complementary } \\
\text { resources such as financial } \\
\text { resources, human resources, ... in } \\
\text { marketing and production } \\
\text { processes }\end{array}$ & $\begin{array}{l}\text { Shane \& Venkataraman (2003); } \\
\text { King, Covin \& Harvey Hegarty } \\
(2003)\end{array}$ \\
\hline Networks & $\begin{array}{l}\text { Entering to new markets for new } \\
\text { products }\end{array}$ & $\begin{array}{l}\text { Antoncic \& Prodan (2008); } \\
\text { Prodan(2007) }\end{array}$ \\
\hline $\begin{array}{l}\text { Research and Development } \\
\text { (R\&D) }\end{array}$ & $\begin{array}{l}\text { Creation of independent and } \\
\text { semi-independent R\&D units }\end{array}$ & $\begin{array}{l}\text { Antoncic \& Prodan } \\
\text { Menzel, Aaltio \& Ulijn } \\
\text { Prodan (2008); } \\
\text { (2007) }\end{array}$ \\
\hline $\begin{array}{l}\text { New Product Development } \\
\text { (NPD) }\end{array}$ & $\begin{array}{l}\text { Innovation in product } \\
\text { commercialization processes }\end{array}$ & $\begin{array}{l}\text { Petti \& Zhang (2011a); Petti \& } \\
\text { Zhang (2011b); Petti (2009) }\end{array}$ \\
\hline
\end{tabular}

\section{Results}

In the qualitative stage of the research after conducting the interviews, the four issues according to the background research including "internal processes", "individual factors", "institutions" and "external networks" have been classified and drawn from the interviews, in the course of the investigations and open and half-structured interviews from the experts and reviewing the documents, the dimensions of the background research have been confirmed, the frequency of the effective factors on technological entrepreneurship according to the views of the experts present in the study are shown in figure 1.

In the quantitative stage using mean test and binominal test, the resulting factors of the qualitative tagged have been examined. Using mean test the effect of the extracted factors have been studied and using binominal test the status of the factors and variables of the technological entrepreneurship in Iranian Nanotechnology SMEs have been assessed. 
Figure 1: The frequency of effective factors on technological entrepreneurship based on the interviews

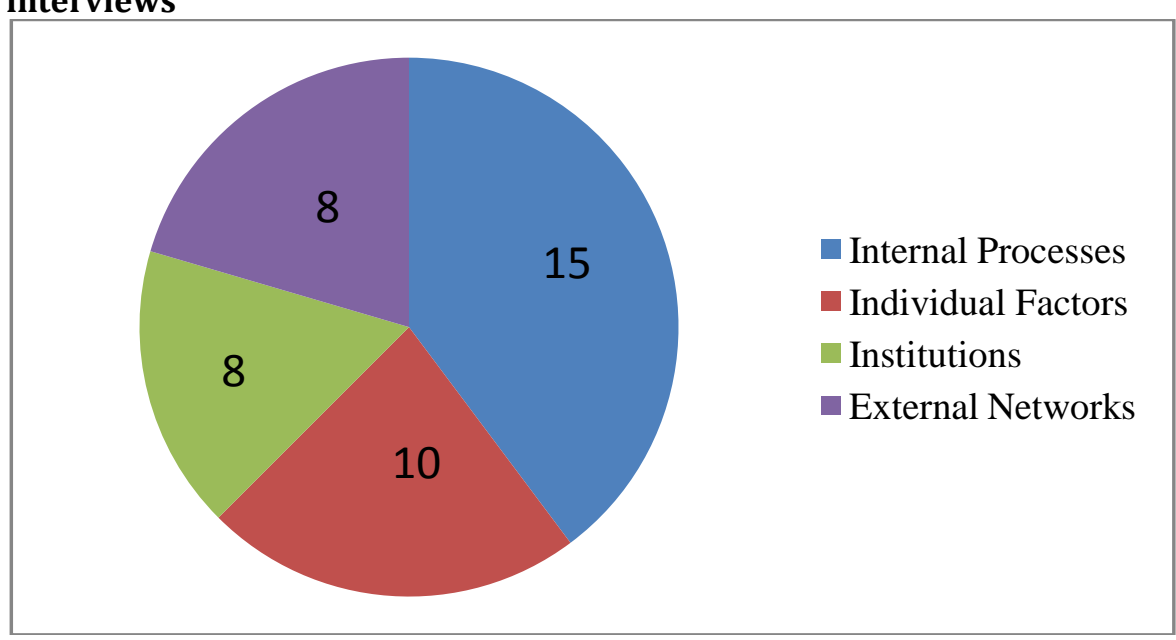

Table 2: Effective factors on technological entrepreneurship Mean Test

\begin{tabular}{lllllll}
\hline Row & Variable & Mean & Test Value & Test & meaning & \multicolumn{2}{c}{$\begin{array}{c}\text { Assurance Distance } \\
\text { High }\end{array}$} & Low \\
\hline 1 & Internal Processes & 2.88 & 3 & 0.963 & -0.423 & -0.075 \\
2 & Individual Factors & 2.76 & 3 & 0.751 & -0.603 & -0.254 \\
3 & Institutions & 2.53 & 3 & 0.654 & -0.605 & -0.244 \\
4 & External Networks & 2.51 & 3 & 0.512 & -0.942 & -0.545 \\
\hline
\end{tabular}

Subject to the table 2, as the resulting means are smaller than test value (3) and also the test meaning levels are greater than error amount (0.05), thus the $\mathrm{H} 0$ theory is rejected and as the assurance distance in the two high domains and low domains are negative, therefore, by a 95 percent confidence we can claim that internal processes, individual factors, institutions and external networks are effective factors on technological entrepreneurship in Iranian Nanotechnology SMEs. The result of two-sentence test of the questions on effective factors on technological entrepreneurship shows that with a 95 percent about the internal processes it can be said that organizational culture in Iranian Nanotechnology SMEs is almost suitable. Nanotechnology development in Iranian Nanotechnology SMEs is not suitable. Management styles suitable in Iranian Nanotechnology SMEs. Research and development (R\&D) is medium in Iranian Nanotechnology SMEs. Organizational learning is little in Iranian Nanotechnology SMEs. Change management is not suitable in Iranian Nanotechnology SMEs. Process and infrastructures are suitable designed in Iranian Nanotechnology SMEs. New product development has not a clear process in Iranian Nanotechnology SMEs. Business model in Iranian Nanotechnology SMEs is not well designed. Organizational structure is flat in Iranian Nanotechnology SMEs. Complementary resources are not well available in Iranian Nanotechnology SMEs.

About the status of individual factors, it can be said that with 95 percent confidence, technical skills such as expertise in nanotechnology and experience in nanotechnology among employees of Iranian Nanotechnology SMEs are high. Meanwhile, entrepreneurial skills such as creativity and innovation, opportunity taking, risk taking, need for achievement and center of inner control are not in a good status among the employees of the Iranian Nanotechnology SMEs. About the institution status, it can be said with a 95 percent confidence that there are no enough financial and legal supportive institutions in Iranian Nanotechnology SMEs. In addition, there is not clear information supporting about the patent activities in Iranian Nanotechnology SMEs. In addition, the relationship between Iranian Nanotechnology SMEs and universities, research centers and science parks, in overall scientific and research supporting is not suitable. However, incentive supporting from activity of Iranian Nanotechnology SMEs is almost suitable. About the external networks status, it can be said with a 95 percent confidence that there are not suitable networks between competitors in Iranian Nanotechnology SMEs. However, some networks between customers and these SMEs have been created. Meanwhile, there are not suitable networks between suppliers and Iranian Nanotechnology SMEs yet. 


\section{Discussion and Conclusion}

Among the findings of the current article, in the components of "internal processes" factor, complimentary resources were identified as the most important factor in technological entrepreneurship for Iranian Nanotechnology SMEs. In addition, the need for technology strategy, formulation of these strategies, and coordination between corporate strategy and technology strategy are some of the concerns and weaknesses of Iranian Nanotechnology SMEs. This confirms the conclusions of Shane and Venkataraman (2003) and King, Covin \& Harvey-Hegarty (2003). Furthermore, in the present research it was concluded having a good "business model" to make competitive advantage against competitors is a key aspect of internal processes affecting technological entrepreneurship. This supports the research results of Menzel, Aaltio and Ulijn (2007), Petti (2009); Petti and Zhang (2011a).Due to their small and medium size and technology-based nature, nanotechnology firms often have a flat organizational structure. Which means the distance between the body of experts and top management is short. Thus, it could be expected that technological entrepreneurship in such firms would be most effective. This confirms the results of Petti and Zhang (2011). "Individual factors" is the second effective factors identified in the present research. It comprises the skills required by individuals and teams wanting to recognize nanotechnology opportunities and exploit them through the process of commercialization. These skills were classified in three different categories: "entrepreneurial skills" and "technical skills". In fact, the findings of the present paper indicate that in order to achieve the goals of technological entrepreneurship in Iranian Nanotechnology SMEs, not only nanotechnology expertise but also entrepreneurial and business skills are required from the human force of such SMEs. This supports the findings of Menzel, Aaltio and Ulijn (2007) and Prodan (2007). The third effective factor of the present article is "institutions". Research in Iranian Nanotechnology SMEs indicates that there are not enough financial institutions to grant financial facilities to these SMEs. Furthermore, there is no institution special to nanotechnology industry that links venture capitalists to companies with new ideas. Institutions like Iran Nanotechnology Initiative Council are built offering services such as: encouraging support (including: research support, invention support, job creation support and support of incubators), nanotechnology education, laboratory networks creation, standardization committee, intellectual property, nanotechnology future study and commercialization to nanotechnology firms and individuals.

Nanotechnology Commercialization Corridor of the Iranian Center of New Industries is another institution that offers specialized commercialization services to nanotechnology firms. Most of the nanotechnology firms in this research are in contact with the aforementioned institutions. However, they were unable to use these facilities and services to their full potential. Universities and research centers played their educational role in nanotechnology satisfactorily. However, university research and development, academic spin-off creation and relations with the industry are still emerging. Meanwhile, science and technology parks support the establishment of nanotechnology businesses by granting financial facilities, but their measures are not enough. The importance of the latter finding confirms the hypotheses of Petti and Zhang (2011a), Petti and Zhang (2011b), Prodan (2007). "External networks" is the last effective factors identified in the present research. Research in Iranian Nanotechnology SMEs indicates networking with customers provokes commercialization ideas and then network ties with venture capitalists make financial resources accessible. This is especially important for nanotechnology firms in their initial phases of establishment, when there is on-going research and development activities but the firm is not yet profitable. Besides, Iran Nanotechnology Initiative Council on its own has provided these firms with a valuable intra-organizational network, which has been very effective in ties with customers, suppliers, competitors and science and technology parks. Furthermore, the innovative action of Nanotechnology Initiative Council in networking nanotechnology laboratories has significantly increased and emphasized the connections of nanotechnology firms with each other as well as implementation of joint projects and joint research and development activities. This confirms the research results of Petti and Zhang (2011a), Petti and Zhang (2011b). Subject to the findings of the current research and previous studies, two suggestions of the paper resulting from the study and for the use of other researchers is presented here:

- How to identify, discover and create opportunities that convert nanotechnology to products (products and services)?

- How to gather the essential resources and manage the connection between nanotechnology science and entrepreneurship in order to develop new products, exploit nanotechnology opportunities and create new markets? 


\section{References}

Antoncic, B. \& Prodan, I. (2008). Alliances, corporate technological entrepreneurship and firm performance: Testing a model on manufacturing firms. Technovation, 28, 257-265.

Blanco, S. (2007). How techno-entrepreneurs build a potentially exciting future? Handbook of Research on Techno-Entrepreneurship, (ed.) by Francois Therein, Edward Elgar, 3-25.

Burgelman, R. A., Christensen, C. M. \& Wheelwright, S. C. (2004). Strategic management of technology and innovation, New York: McGraw Hill.

Dahlstrand, A. L. (2007). Technology-based entrepreneurship and regional development: the case of Sweden. Journal of European Business Review, 19(5), 373-386.

Dorf, R. C. \& Byers, T. H. (2005). Technology ventures: From idea to enterprise. New York: McGraw-Hill.

Garud, R. \& Karnøe, P. (2003). Birocolage versus breakthrough: distributed and embedded agency in technology entrepreneurship. Journal of Research Policy, 32 277-300.

King, D. R., Covin, J. G., Harvey-Hegarty, W. (2003). Complementary Resources and the Exploitation of Technological Innovations. Journal of Management, 29(4), 589-606.

Menzel C. M., Aaltio, I. \&Ulijn, J. M. (2007). On the way to creativity: Engineers as entrepreneurs in organizations. Technovation, 27(12), 732-743.

Peng, X. \& Zhang, G. (2008). The moderating effect of governance form on the relationship between corporate technological entrepreneurship activities and corporate financial performance: An empirical study on Chinese high-tech firms. Journal of PICMET Proceedings, 27-31 July, Cape Town, South Africa.

Peng, X., Ni, X. \& Yao, C. (2008). The influence of governance form on the utility of corporate technological entrepreneurship activities; empirical studies on Chinese bio-pharmaceutical Industry. Journal of Proceedings of the IEEE ICMIT, 576- 581.

Petti, C. (2009). Cases in technological entrepreneurship: Converting ideas into value. Edward Elgar.

Petti, C. \& Zhang, S. H. (2011a). Factors influencing technological entrepreneurship capabilities towards an integrated research framework for Chinese enterprises. Journal of Technology Management in China, 6(1), 7-25.

Petti, C. \& Zhang, S. H. (2011b). Explaining Technological Innovation in Chinese Enterprises: Insights from Technological Entrepreneurship. Journal of Front. Bus. Res. China, 5(3), 452-471.

Prodan, I. (2007). A model of technological entrepreneurship, In: Handbook of Research on TechnoEntrepreneurship, (ed.) Francois Therein, Edward Elgar.

Shane, S. \& Venkataraman, S. (2003). Guest editors`introduction to the special issue on technology entrepreneurship. Journal of Research Policy, 32, 181-184.

Worthington I. \& Britton, C. (2006). The business environment (6th ed.,) Pearson Education Limited.

Zahra, S. A. \& Nielsen, A. P. (2002). Sources of capabilities, integration and technology commercialization. Journal of Strategic Management, 23(5), 377-398.

Zhang, G., Peng, X. \& Li, J. (2008). Technological entrepreneurship and policy environment: a case of China. Journal of Small Business and Enterprise Development, 15(4), 733-751. 